\title{
A Response to: Letter to the Editor Regarding "Gabapentin has Longer-Term Efficacy for the Treatment of Chronic Pelvic Pain in Women: A Systematic Review and Pilot Meta-analysis"
}

\author{
Yi-Feng Ren · Xiu-Mei Fan · Xi Fu $\cdot$ Hao Wu $\cdot$ Xin Ye \\ Yi-Fang Jiang $\cdot$ Feng-Ming You (D)
}

Received: November 18, 2021 / Accepted: December 21, 2021 / Published online: January 19, 2022

(c) The Author(s) 2022

Keywords: Chronic pelvic pain; Gabapentin; Longer-term benefits

Yi-Feng Ren and Xiu-Mei Fan contributed equally to this work as co-first authors.

Y.-F. Ren · X.-M. Fan · X. Fu · H. Wu $\cdot$ X. Ye .

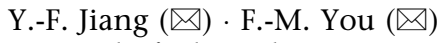

Hospital of Chengdu University of Traditional

Chinese Medicine, Chengdu 610072, Sichuan

Province, China

e-mail: jyftcm@163.comF.-M. You

e-mail: yfmdoc@163.com

Y.-F. Jiang · F.-M. You

TCM Regulating Metabolic Diseases Key Laboratory

of Sichuan Province, Hospital of Chengdu

University of Traditional Chinese Medicine,

Chengdu 610072, Sichuan Province, China

\section{Key Summary Points}

Although several clinical studies have evaluated gabapentin for the treatment of chronic pelvic pain in women, efficacy and safety of this therapy remains controversial.

The published meta-analysis evaluated efficacy and safety of gabapentin for treatment of chronic pelvic pain in women, and the results revealed that gabapentin has potential analgesic effects in this group of patients.

This is a response article to: Letter to the Editor regarding "Gabapentin has LongerTerm Efficacy for the Treatment of Chronic Pelvic Pain in Women: A Systematic Review and Pilot Metaanalysis".

Dear Editor,

Thank you for informing us about the letter discussing the results of "Gabapentin has Longer-Term Efficacy for the Treatment of Chronic Pelvic Pain in Women: A Systematic Review and Pilot Meta-analysis" [1]. Meanwhile, 


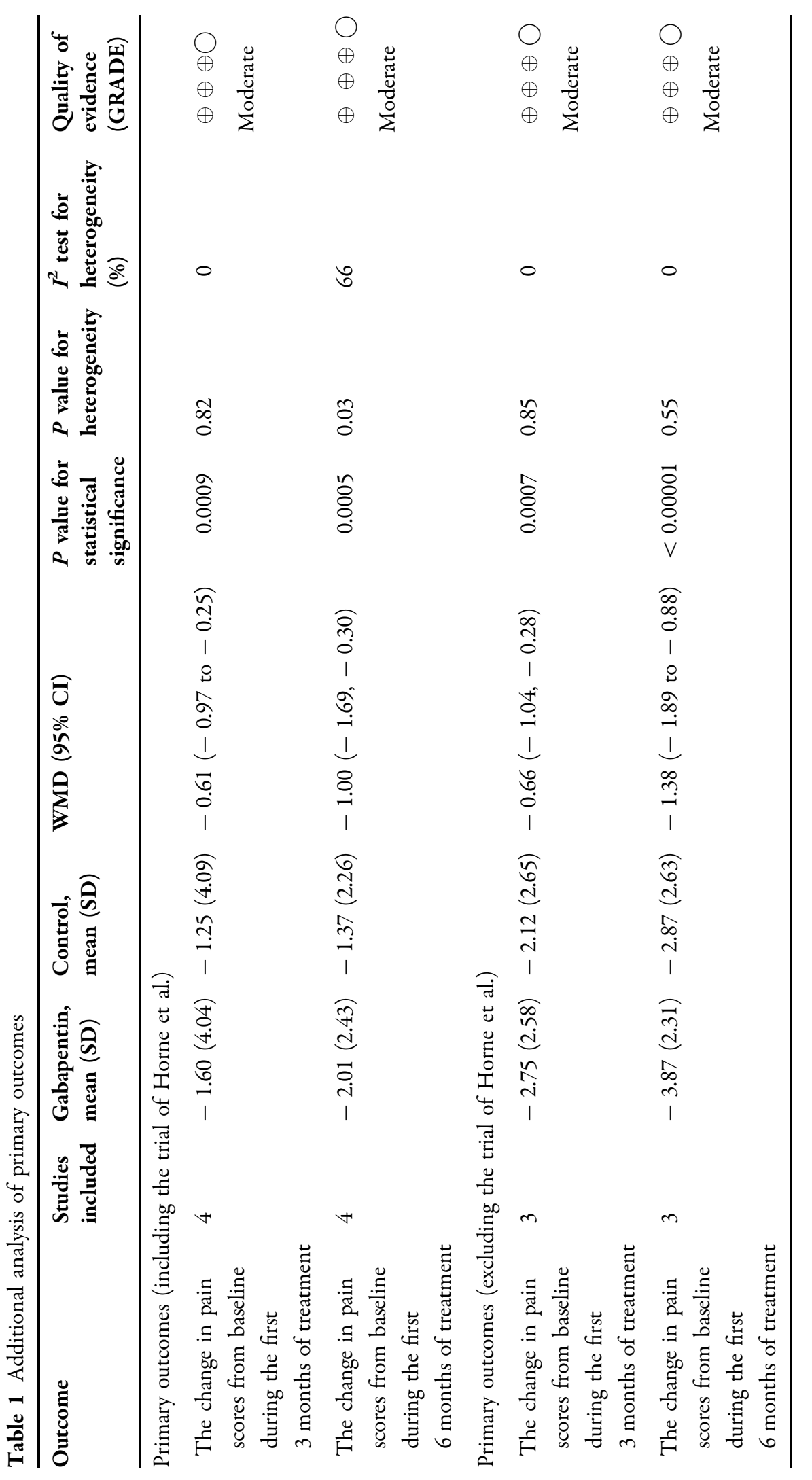


we also appreciate the comments by Vincent et al. about our research.

In relation to their first comment, we certainly agree that Vincent et al. conducted a high-quality study about the efficacy and safety of gabapentin treatment for chronic pelvic pain (CPP) in women [2]. Their outcome variables were assessed during 13 to 16 weeks, which were far shorter than 6 months (24 weeks). Therefore, this outcome was not included in our pilot meta-analysis of 'the change in pain scores from the baseline during the first 6 months treatment'. However, in order to eliminate potential misunderstanding, we did an additional analysis of data of Horne et al. in this response article. The results showed that neither including nor excluding the trial of Horne et al. had a significant alteration for the primary outcomes (see Table 1). Besides, it is noteworthy that our results [1] are consistent with those from Lewis et al., 2016, which conducted by their team [3]. Similarly, Putzke and colleagues also found that gabapentin had a longer-term analgesic effect (3 years) for pain after traumatic spinal cord injury [4]. Finally, Biggs et al. demonstrated that gabapentin exerted longterm effects on pain relief from the angle of animal experiments [5]. Therefore, there are currently potential clinical, experimental, and statistical evidence about the long-term effects in the gabapentin treatment for CPP in women, and it is necessary and meaningful to design more high-quality studies for further clarification.

Second, regarding 'the use of change in pain scores' as an indicator to evaluate the degree of pain improvement, we consider it is reasonable. There are some reasons: (i) In the present analysis, the change in pain scores was calculated as pain score at 3 months or 6 months minus baseline pain scores. Thus, it had already been taken into account of baseline pain severity, and could further strengthen the external validity. (ii) The change in pain score was the most frequently reported outcome in all included studies. (iii) There have been a number of past high-quality studies using "the change in pain scores" as the primary outcome measures [6-8]. (iv) We applied the minimally clinically important difference (MCID) to interpret results on the change in pain scores from baseline to 3 months and 6 months. Likewise, when formulating the MCID, the effect of baseline pain was considered [9].

Third, we agree with Vincent et al. that there is a risk of gabapentin-related adverse events in the treatment of CPP in women. As such, we also suggested that 'patients with major neurologic conditions are advised to avoid gabapentin-based treatment' in the discussion section of the paper [1]. Additionally, Horowitz et al. also showed that further studies were needed to assess the long-term efficacy and safety of gabapentin for patients with anxiety and other mental health conditions [10]. In fact, although there were some adverse events, our results showed that gabapentin was also an effective treatment option for patients with CPP [1]. Of note, more recently, epidemiological studies confirmed that the gabapentinoids appeared to possess no addictive potential themselves, and even had a positive benefit in clinical therapeutics [11].

Finally, we also agree that it is very hard to draw a solid conclusion on the basis of such a small sample size. We also acknowledge that the possibility of small sample effect cannot be fully ruled out, despite the homogeneity of data dilutes this possibility. Therefore, the finding of this pilot meta-analysis needs to be considered exploratory and interpreted with caution, and the high-quality studies are needed to verify the efficacy of gabapentin treatment for CPP in women.

We deeply thank Vincent et al. and colleagues again for their contribution to this discussion and would welcome any other criticism.

\section{ACKNOWLEDGEMENTS}

Funding. No funding or sponsorship was received for this study or publication of this letter.

Authorship. All named authors meet the International Committee of Medical Journal Editors (ICMJE) criteria for authorship for this article, take responsibility for the integrity of 
the work as a whole, and have given their approval for this version to be published.

Author Contributions. Yi-Feng Ren: Statistical Analysis, Writing-original draft, Validation. Xiu-Mei Fan: Writing-original draft, Validation. Xi Fu: Data collection, Methodology, Writing-original draft, Validation. Hao Wu: Data collection, Methodology, Validation. Xin Ye: Data collection, Validation. Yi-Fang Jiang: Conceptualization, Writing-review \& editing, Validation. Feng-Ming You: Conceptualization, Methodology, Writing-review \& editing, Validation.

Disclosures. Yi-Feng Ren, Xiu-Mei Fan, Xi $\mathrm{Fu}, \mathrm{Hao} \mathrm{Wu}$, Xin Ye, Yi-Fang Jiang, and FengMing You have nothing to disclose.

Compliance with Ethics Guidelines. This article is based on previously conducted studies and does not contain any new studies with human participants or animals performed by any of the authors.

Data Availability. The datasets generated during and/or analyzed during the current study are available from the corresponding author on reasonable request.

Open Access. This article is licensed under a Creative Commons Attribution-NonCommercial 4.0 International License, which permits any non-commercial use, sharing, adaptation, distribution and reproduction in any medium or format, as long as you give appropriate credit to the original author(s) and the source, provide a link to the Creative Commons licence, and indicate if changes were made. The images or other third party material in this article are included in the article's Creative Commons licence, unless indicated otherwise in a credit line to the material. If material is not included in the article's Creative Commons licence and your intended use is not permitted by statutory regulation or exceeds the permitted use, you will need to obtain permission directly from the copyright holder. To view a copy of this licence, visit http://creativecommons.org/licenses/bync/4.0/.

\section{REFERENCES}

1. Fan XM, Ren YF, Fu X, et al. Gabapentin has longerterm efficacy for the treatment of chronic pelvic pain in women: a systematic review and pilot metaanalysis. Pain Ther. 2021;10:1673-89. https://doi. org/10.1007/s40122-021-00330-4.

2. Horne AW, Vincent K, Hewitt CA, et al. Gabapentin for chronic pelvic pain in women (GaPP2): a multicentre, randomised, double-blind, placebo-controlled trial. Lancet. 2020;396:909-17. https://doi. org/10.1016/S0140-6736(20)31693-7.

3. Lewis SC, Bhattacharya S, Wu O, et al. Gabapentin for the management of chronic pelvic pain in women (GaPP1): a pilot randomised controlled trial. PLOS ONE. 2016;11: e0153037. https://doi. org/10.1371/journal.pone.0153037.

4. Putzke JD, Richards JS, Kezar L, Hicken BL, Ness TJ. Long-term use of gabapentin for treatment of pain after traumatic spinal cord injury. Clin J Pain. 2002;18:116-21. https://doi.org/10.1097/ 00002508-200203000-00007.

5. Biggs JE, Boakye PA, Ganesan N, et al. Analysis of the long-term actions of gabapentin and pregabalin in dorsal root ganglia and substantia gelatinosa. J Neurophysiol. 2014;112:2398-412. https://doi. org/10.1152/jn.00168.2014.

6. Busse JW, Wang L, Kamaleldin M, et al. Opioids for chronic noncancer pain: a systematic review and meta-analysis. JAMA. 2018;320:2448-60. https:// doi.org/10.1001/jama.2018.18472.

7. Kemp JL, Mosler $\mathrm{AB}$, Hart $\mathrm{H}$, et al. Improving function in people with hip-related pain: a systematic review and meta-analysis of physiotherapist-led interventions for hip-related pain. $\mathrm{Br} \mathrm{J}$ Sports Med. 2020;54:1382-94. https://doi.org/10. 1136/bjsports-2019-101690.

8. Lim EC, Tay MG. Kinesio taping in musculoskeletal pain and disability that lasts for more than 4 weeks: is it time to peel off the tape and throw it out with the sweat? A systematic review with meta-analysis focused on pain and also methods of tape application. Br J Sports Med. 2015;49:1558-66. https://doi. org/10.1136/bjsports-2014-094151.

9. Salaffi F, Stancati A, Silvestri CA, Ciapetti A, Grassi W. Minimal clinically important changes in chronic musculoskeletal pain intensity measured on a numerical rating scale. Eur J Pain. 2004;8: 283-91. https://doi.org/10.1016/j.ejpain.2003.09. 004.

10. Horowitz MA, Kelleher M, Taylor D. Should gabapentinoids be prescribed long-term for anxiety 
and other mental health conditions? Addict Behav. 2021;119: 106943. https://doi.org/10.1016/j. addbeh.2021.106943.
11. McAnally H, Bonnet U, Kaye AD. Gabapentinoid benefit and risk stratification: mechanisms over myth. Pain Ther. 2020;9:441-52. https://doi.org/10. 1007/s40122-020-00189-x. 